\title{
CHILD LABOR AND SCHOOLING IN BOLIVIA: WHO'S FALLING BEHIND? THE ROLES OF DOMESTIC WORK, GENDER AND ETHNICITY
}

\author{
Autor:
}

\author{
Dante Contreras, \\ Daniela Zapata y Diana \\ Kruger
}

Santiago, Abr. 2007 


\title{
Serie Documentos de Trabajo
}

N 234

\section{CHILD LABOR AND SCHOOLING IN BOLIVIA: WHO'S FALLING BEHIND? THE ROLES OF DOMESTIC WORK, GENDER AND ETHNICITY}

\author{
Dante Contreras \\ Departamento de Economía \\ Universidad de Chile \\ Daniela Zapata \\ UN Economic Commission for \\ Latin America and the Caribbean \\ Diana Kruger \\ Pontificia Universidad Católica \\ de Valparaíso, Chile
}

\begin{abstract}
We analyze the work-school tradeoff among Bolivia's children. We compare a definition of work that includes only market activities and one that also considers domestic chores. Our empirical specification considers the joint determination of these decisions. We find that a tradeoff exists and that gender and ethnicity matter. Boys are more likely to work if pure market activities are considered; once domestic tasks are included girls are twice as likely to work than boys. The tradeoff between school and work is stronger for indigenous children, and indigenous girls are falling behind other children in terms of their human capital accumulation.
\end{abstract}

Palabras Claves: Bolivia, ethnicity, gender, child labor, domestic work, schooling, Latin America.

JEL Classification: D13, J15, J16, J22, J24, O15 


\title{
Child labor and schooling in Bolivia: Who's falling behind? The roles of domestic work, gender and ethnicity
}

\author{
Daniela Zapata \\ UN Economic Commission \\ for Latin America and the \\ Caribbean
}

\author{
Dante Contreras \\ University of Chile
}

\author{
Diana Kruger* \\ Pontificia Universidad \\ Católica de Valparaíso, Chile
}

\begin{abstract}
We analyze the work-school tradeoff among Bolivia's children. We compare a definition of work that includes only market activities and one that also considers domestic chores. Our empirical specification considers the joint determination of these decisions. We find that a tradeoff exists and that gender and ethnicity matter. Boys are more likely to work if pure market activities are considered; once domestic tasks are included girls are twice as likely to work than boys. The tradeoff between school and work is stronger for indigenous children, and indigenous girls are falling behind other children in terms of their human capital accumulation.
\end{abstract}

Key words: child labor, domestic work, schooling, gender, Latin America, Bolivia

JEL Classification: D13, J15, J16, J22, J24, O15

\footnotetext{
* Kruger received financial support from Chile's National Science and Technology Research Commission (CONICYT), through FONDECYT Project No. 1070447. Jose Miguel Benavente, Claudia Sanhueza and Marcelo Ochoa provided numerous comments and suggestions, we are also grateful for the comments of the participants of the Latin American Meeting of the Econometric Society (July, 2004) and the participants of the meeting of the Society of Economists of Chile (September, 2004.) All errors and omissions are the responsibility of the authors. Kruger is the corresponding author: diana.kruger@ucv.cl
} 


\section{Introduction}

Child labor is a common phenomenon in poor countries. Despite the fact that most countries adhere to international conventions to curtail child labor, millions of children in LDCs are seen working daily as street vendors or shoe shiners. If working as a child translates into lower educational attainment, then the future economic well-being of children might be in jeopardy since education is one of the most important tools to increase income and escape from poverty.

In recent years, there has been a proliferation of empirical work on child labor, which has given a better understanding of its causes and of the consequences of different policy interventions. ${ }^{1} \quad$ The official definition of child labor by the International Labour Organization includes children who work in economic activities, which comprise all market production (paid work) and certain types of non-market production (unpaid work), including the production of goods for self-consumption. Researchers have used several definitions of child labor to capture the concept behind the ILO definition. For example, most authors define working children as those who are economically active or as children who work in market-oriented activities, while others consider only children who work outside the home (Gunnarson et al., 2004) or children who have positive labor earnings (Moehling 2005).

A less explored area of research is the role that domestic work plays in the school-work tradeoff, and to what extent — if any at all—domestic activities displace schooling. Girls' educational outcomes are of particular importance in the work-school debate, since economists agree almost unanimously that the education of girls has externalities that benefit society as a whole: in addition to individual earnings and labor market performance, girls' education is a crucial factor for improving family health and lowering birth rates (Schultz, 2001). 
From a policy perspective, child work is harmful if it interferes with children's health or educational advancement, since lower educational attainments are correlated with future poverty. Domestic activities, on the other hand, do not have negative connotations, and they are not considered a threat to children's future economic outcomes. Nonetheless, domestic work is not gender-neutral: its exclusion from child labor definitions affects girls more severely, since they are usually the ones who undertake such activities (Edmonds 2006, Levison and Moe, 1998).

In this sense, it is important to include all work that children perform-inside and outside the home - to accurately assess its potentially negative effects. Omitting household responsibilities from the definition of child labor could explain why most empirical evidence has found that boys are more vulnerable to the negative effects child labor. By ignoring domestic work, an important group of girls has been left out of the scope of policies oriented towards increasing schooling and reducing child labor.

Among the studies that have previously analyzed the role of domestic work in children's outcomes is Levison and Moe (1998), which estimated the determinants of domestic work and schooling among unmarried girls aged 10 to 19 in Peru. They find that family income reduces the probability that a girl performs chores and that conditional on performing chores, better socioeconomic variables reduce the number of hours spent on chores and increase the number of hours spent on school. Levinson et al. (2001) estimated the determinants of the four possible time-allocation decisions (studying only, working only, concurrent studying and working, or doing neither) of youth aged 12 to 17 years in urban Mexico. They compared definitions of work with and without household chores and found that once domestic work is included, young girls are 7.7 percentage points less likely to specialize in school than boys.

More recently, Amin et. al (2006) studied the determinants of the probabilities that children perform market, domestic and both types of work together using data from the 1995- 
1996 Bangladesh Household Expenditure Survey. Their results indicate that both market and household work are negatively correlated with different measures of schooling, although they do not explicitly model the joint nature of these decisions. Kruger and Berthelon (2007) estimate a multinomial model for Brazilian children between 10-14 years old and found that once household work is taken into consideration Brazilian girls are more likely to work and less likely to be on school than boys.

In this paper we analyze the decisions of child work and schooling in Bolivia, emphasizing the role of domestic work in the schooling decision. We are especially concerned with girls' outcomes because Bolivia's labor market has large gender disparities: unemployment rates are higher among women, they earn less than men do, and they work in lower-quality jobs. If we consider that education is a crucial determinant in labor market outcomes, then girls' success in early educational outcomes is important in attenuating such biases in the future.

This investigation contributes to the existing child labor literature along several dimensions. First, unlike most of the studies that analyze domestic work, we focus on a more vulnerable group of young boys and girls who are of primary school age (7 to 14 years). The analysis of older and younger children differ because younger children may be less able physically to combine market work with school, so that initiating work at a young age is possibly correlated with or dropping out before finishing primary education or staying out of the school system altogether. Furthermore, it is possible that working at a young age conflicts more severely with the attainment of basic skills, which is attenuated in older students who have already acquired some literacy and numeric skills (Gunnarsson et al., 2004).

Secondly, we analyze if the work-school tradeoff differs across ethnic lines. A large proportion of Bolivia's population is indigenous, ${ }^{2}$ and it has lagged behind other groups for centuries in terms of human development indicators, continuing to have limited economic 
opportunities today. Bolivia is a poor country -64 percent of the population lives in povertyand the indigenous population represents a disproportionate share of the country's poor. This is in turn correlated with low education, poor health outcomes and low incomes in general. Average household income per capita is about 60 percent lower among indigenous households, which could in part be explained by lower educational attainments: compared to the nonindigenous, indigenous workers have about 4 less years of schooling. Thus, a study that analyzes Bolivia must consider whether differences exist between non-indigenous and indigenous populations, especially in early educational outcomes.

Finally, unlike previous studies, in our empirical specification the work and schooling decisions are jointly determined, which allows us to test if there is indeed a trade-off between the two, and if this trade-off is sensitive to the definition of work.

We perform our analysis using two definitions of labor, one that measures only marketoriented activities, which we label the "restrictive" definition and a second more "inclusive" definition that considers hours dedicated to domestic work. This contrast allows us to asses whether — and to what extent—child labor is underestimated when a restrictive definition of market work is used.

In all the estimations we performed, we found a negative and statistically significant correlation between the school and work decisions and that the trade-off is larger with the pure market definition of work. We also find that without domestic tasks in the definition, boys are more likely to work than girls are, but that with the inclusive definition of work, girls are $100 \%$ more likely to work than boys.

Indigenous girls are just as likely as indigenous boys to work in the market and more likely to work in market and domestic tasks. Furthermore, indigenous girls are less likely to be enrolled in school than indigenous boys, suggesting that indigenous girls are a particularly 
vulnerable group in terms of educational outcomes.

We also find that even low levels of education of the household head reduce the probability that children perform market-oriented work, but that a decrease in the likelihood that children perform market + domestic work requires that the household head has completed secondary education or more. Further, we found that the presence of a woman older than 19 years of age in the household reduces the probability of performing market + domestic work, and it increases and the probability that a boy attends to school.

The rest of the paper unfolds as follows. The next section describes the patterns of child labor and schooling in Bolivia, followed by a section describing the data and the methodological approach. The fourth section contains a summary of the estimation results. We conclude with a fifth section of final remarks and policy implications.

\section{School and work among Bolivian children}

The educational system of Bolivia consists of eight years of compulsory primary education for children aged 6 and older. Most schools - both public and private - operate up to two daily shifts of approximately 5 hours. Due in part to a national education reform, by 2001 the primary enrollment rate in Bolivia was almost 94 percent for both boys and girls. ${ }^{3}$ Although there is no apparent gender gap in enrollment, a greater proportion of Bolivian girls never enter the formal school system (ECLAC, 2004) and among children that do enroll in school, 24 percent of girls drop out before completing primary school compared to 19 percent of boys. Meanwhile, the outcome gaps are even greater along ethnic lines: 42 percent of indigenous children drop out before primary school completion compared to 14 percent of non-indigenous children. ${ }^{4}$ Although there are several ways to define indigenous, we classified children based on their mother tongue. 
Bolivian data reveal that most children participate in domestic tasks, that they spend many hours in these activities, and that these are unevenly distributed according to a child's sex and ethnicity. Approximately 87 percent of children aged 7 to 14 reported spending at least an hour on household chores during previous week (Table 1), and domestic activities are more common among girls: 90 percent of them did chores, compared to 84 percent of boys. Furthermore, Bolivian children spend an average of 14.5 hours per week-roughly 2 hours daily — performing chores, and girls spent about five more weekly hours on these activities than boys (almost 17 versus 12 hours, respectively). Domestic work is also more common among indigenous (92 percent) than non-indigenous ( 85 percent) children, although conditional on performing domestic tasks they work similar numbers of hours.

\section{[INSERT TABLE 1 HERE ]}

Table 1 also reveals that market work is more common among boys and among indigenous children: 32 percent of boys reported working one or more hours in the market, compared to 25 percent of girls, and almost 60 percent of indigenous worked 1 hour or more in the market vs. 19 percent of non-indigenous children. Furthermore, working children spend an average of 21 weekly hours dedicated to market activities, which is equivalent to 4 hours per day during the school week.

If total work is considered, 86 percent of girls perform some kind of work activity compared to 80 percent of boys, and 92 percent of indigenous children worked compared to 80 percent of non-indigenous. Domestic and/or market work sum to an average of 22 weekly hours devoted to tasks that conflict directly with educational activities. If working children achieve lower levels of education, they will be more vulnerable to poverty as adults.

Since we are interested in analyzing the work activities performed by children that can potentially harm their schooling achievements, in this study we define child laborers as children 
aged 7-14 years of age who work 20 hours or more per week. ${ }^{5}$ In order to be able to asses the role of domestic work, we perform the analysis using two definitions: the first, more restrictive measure includes only market labor activities, which refers to any activity whose final goal is the market (including agriculture, food preparation for retail, family business activities and informal commerce). The second and more inclusive definition also considers hours dedicated to domestic work.

Bolivia's educational system allows children to work part-time, since the school day lasts only 5 hours. As a result, an important percentage of children combine work and schooling. Our definition of schooling is based on available information regarding whether children are enrolled in school. Table 2 summarizes how children allocate their time between the two activities in Bolivia across gender lines and ethnicity, using our two definitions of work. We see that with a restrictive, market definition, the incidence of work is similar for boys and girls: 11 percent of boys reported working 20 weekly hours or more-either exclusively $(2 \%)$ or while in school (9\%), compared to 10 percent of girls. A different picture emerges with the more inclusive definition of work that includes domestic activities: 42 percent of girls report working at least 20 weekly hours, compared to 30 percent of boys, which suggests that omitting domestic tasks from the analysis underestimates girls' work, and consequently its impact on schooling.

\section{[ INSERT TABLE 2 HERE ]}

Table 2 also reveals that indigenous children are more likely to work than the nonindigenous with both definitions. The market work rate of indigenous children ( 20 percent) is more than two times greater than the work rate for non-indigenous ( 8 percent). Furthermore, if domestic work is included, almost 50 percent of indigenous children work vis-à-vis 32 percent of non-indigenous.

Figure 1 presents the evolution of the incidence of work as children get older, for boys 
and girls separately using both definitions. We find that if the restrictive definition of work is used, no important gender differences exist in the incidence of child labor at any age; however, the inclusive definition of work reveals that a higher percentage of girls work, and that the gap between market and total work (market + domestic) grows as children get older. Figure 2 compares the evolution of both work definitions along ethnic lines and reveals that indigenous children are more likely to work than non-indigenous with both definitions.

\section{Methodology, Data and Variables}

We model child labor and schooling decisions within a unitary household framework: we assume that a representative agent who wishes to maximize family welfare takes decisions within the household. The unobserved utility levels when child $i$ attend to school and work are defined by the following two equations, respectively:

$$
\begin{aligned}
& U_{i s}{ }^{*}=\beta_{1} X_{i}+\beta_{2} Z_{j} \\
& {U_{i w}{ }^{*}}^{*}=\alpha_{1} X_{i}+\alpha_{2} Z_{j}
\end{aligned}
$$

The explanatory variables $X_{i}$ include child characteristics, $Z_{j}$ is a vector of family characteristics, and $\beta_{1}, \beta_{2}, \alpha_{1}$, and $\alpha_{2}$ are unknown parameters. Given the unobservable factors affecting utility levels, we define error terms $\left(\varepsilon_{S,} \varepsilon_{w}\right)$ so the equations become:

$$
\begin{aligned}
& U_{i s}{ }^{*}=\beta_{1} X_{i}+\beta_{2} Z_{j}+\varepsilon_{i s} \\
& U_{i w}{ }^{*}=\alpha_{1} X_{i}+\alpha_{2} Z_{j}+\varepsilon_{i w}
\end{aligned}
$$

Researchers do not observe these random utility functions, but do have data on children's otucomes. Let $y_{i s}$ and $y_{i w}$ be dummy variables that represent the observed choices made regarding children's time allocation: 


$$
\begin{aligned}
& y_{i s}=\left\{\begin{array}{l}
1 \text { if the child is enrolled in school, which implies that } U_{i s}^{*}>0 \\
0 \text { if the child is not enrolled in school, which implies that } U_{i s}^{*} \leq 0
\end{array}\right. \\
& y_{i w}=\left\{\begin{array}{l}
1 \text { if the child worked more than } 20 \text { hours last week, which implies that } U_{i w}^{*}>0 \\
0 \text { if the child worked less than } 20 \text { hours last week, which implies that } U_{i w}^{*} \leq 0
\end{array}\right.
\end{aligned}
$$

where:

$U_{i s}{ }^{*}$ is a latent variable that represents the family's utility if the child goes to school, and $U_{i w}{ }^{*}$ is a latent variable that represents the family's utility if the child works.

Depending on the unobservable utility levels, the observed outcomes for child $i$, with $i \in I=\{1, \ldots . . n\}$, where $n$ is the number of observations in the sample will be: schooling and no work; schooling and work; work and no schooling, and no schooling no work. Thus, the probability that a child works or attends to school depends on the utility of the child's family, and are given by equations (3) and (4), respectively,

$$
\begin{aligned}
& \operatorname{Pr}\left(y_{i s}=1\right)=\operatorname{Pr}\left(\beta_{1} X_{i}+\beta_{2} Z_{j}+\varepsilon_{j s} \geq 0\right) \\
& \operatorname{Pr}\left(y_{i w}=1\right)=\operatorname{Pr}\left(\alpha_{1} X_{i}+\alpha_{2} Z_{j}+\varepsilon_{j w} \geq 0\right)
\end{aligned}
$$

We will model these outcomes as joint decisions, where the schooling and working choices are correlated.

The dependent variables are $y_{j s}$ and $y_{j w}$, while $X_{i}$ and $Z_{j}$ are the explanatory variables and the vector of error terms is $\eta=\left(\varepsilon_{s,}, \varepsilon_{w}\right)$. We assume that $\eta$ follows a normal distribution with:

$$
\begin{aligned}
& E[\eta]=0 \\
& \operatorname{Var}\left(\varepsilon_{s}\right)=\operatorname{Var}\left(\varepsilon_{w}\right)=1 \\
& \operatorname{Cov}\left(\varepsilon_{s,} \varepsilon_{w}\right)=\rho
\end{aligned}
$$


Since the variances are equal to one, then $\rho$ is also the coefficient of correlation, which indicates whether these two decisions are taken jointly. The parameters $\alpha_{1}, \alpha_{2}, \beta_{1,} \beta_{2}$ and $\rho$ may be obtained through maximum-likelihood estimation. The likelihood function used is:

$$
L=\prod \int_{-\infty}^{\beta^{\prime} X} \int_{-\infty}^{\alpha^{\prime} Y} \phi\left(\varepsilon_{s}, \varepsilon_{w}, \rho\right) d \varepsilon_{s} d \varepsilon_{w}
$$

where $\phi$ is the bivariate normal density function. We thus estimate (5) with a bivariate Probit, which also allows us to test for the existence and significance of the joint nature of these decisions.

\subsection{The Data}

The data used in this study comes from Bolivia's national household survey (MECOVI), administered by the National Statistical Institute during the months of November and December of each year. The MECOVI is a nationally representative survey that contains characteristics for every person in the household. We limit our analysis to data from the 2001 round because this was the only year that included a time-use section with detailed information about domestic activities of household members. In that year, 5,845 households and 25,166 individuals were interviewed. We restrict our sample to children aged between 7 and 14 years, who are related of the household head. Our resulting sub-sample includes 5,277 children, nearly half of which are girls.

\subsection{Dependent Variables}

The dependent variables $y_{j s}$ and $y_{j w}$ correspond to individual children's school and work decisions, respectively. We define a child as being in school if she is reported as being enrolled 
in school. ${ }^{6}$ We analyze two concepts of work: the restrictive definition is a variable that equals 1 if the child reported working 20 or more hours in market-related activities during the previous week, and 0 otherwise. The inclusive more holistic definition of total work (including domestic chores) equals 1 if the child worked 20 or more hours in either market or domestic activities. ${ }^{7}$

Based on these definitions, we find that 11 percent of Bolivian children aged between 7 and 14 years worked more than 20 hours a week in marked-oriented activities in 2001, and if domestic work is included in the definition of labor, about one in three children-36 percentworked more than 20 hours a week (Table 2). Most working children-regardless of the definition used-did so while attending school, which is facilitated by the short school day of Bolivia's education system. Thus, we find that 95 percent of children in our sample are enrolled in school; 86 percent are exclusively in school if the restrictive, market definition of work is used while 62 percent are enrolled exclusively if any both domestic and market work are considered (Table 2).

\subsection{Explanatory Variables}

The vector of exogenous, child-specific variables includes a variable of the child's age, a dummy variable for gender, and dummy variables that indicate whether the child is an indigenous boy or girl.

We include variables that control for the family's demographic composition, such as: number of children younger than 6 years old, number of children aged between 6-18 years other than self, and number of adults other than the parents. ${ }^{8}$ The presence of small children in the household increases the demand for domestic labor dedicated to childcare activities, which probably increases the workloads of older siblings in the household. The effect of the presence of school-aged children (6 to 18 years) on the two dependent variables is ambiguous a priori: on 
one hand, the siblings compete for scarce education resources within the household, so that a larger number may have a negative effect on the likelihood of schooling. On the other hand, the presence of more school-aged children facilitates sharing the burden of domestic tasks, so that the likelihood of schooling of children in our sample may increase.

The presence of other adults in the household (besides the parents) may alleviate some of the burden of domestic chores that children face, so that their attendance to school is more likely. We also include controls for the sex of the head of the household and a dummy if both parents are present in the home.

To capture the effects of family income, we included a variable that measures the educational level of the head of the household as proxy for the family's permanent income. ${ }^{9}$ We did not include household income directly for two reasons: first, it may be endogenously determined by the decision to send a child to work. Second, studies reveal that in societies were the population depends on self-employment or subsistence agriculture or other informal employment, income is inaccurately measured and it may not reflect household welfare. ${ }^{10}$ To capture the effect of differences in wealth, we included dummy variables indicating if the house has piped water and if it has electrical power, which might also affect the amount of time required to perform domestic work.

In rural areas of Bolivia, agricultural child labor is a cultural aspect and is considered part of children's development, while child labor in cities is caused by different factors, such as economic crises or cultural factors of rural immigrants (ILO, 1998). To control for these and other differences between rural and urban areas, we included a dummy variable that indicates whether the household is rural. Finally, we include fixed effects at the municipal level in order to control for permanent differences across municipalities, such as education supply-side factors (availability of schools) and child labor demand-side factors (unemployment rates, economic 
activity). Summary statistics for all variables are found in Table 3.

\section{[ INSERT TABLE 3 HERE]}

\section{Results}

We performed all the estimations for the two definitions of work. Table 4 presents regression results for all children aged 7 to 14 years, while Tables 5 and 6 display the findings for non-indigenous and indigenous children, respectively.

\subsection{Domestic work and gender}

Table 4 reveals that if the definition of child labor considers only market-oriented activities, girls are less likely than boys to be working (Column 1) and they are just as likely to be enrolled in school (Column 2). This result summarizes the findings of most child labor studies: boys are more likely to work than girls are if work is defined as market activities.

\section{[ INSERT TABLE 4 HERE ]}

Once domestic tasks are considered, however, the results are the opposite; in other words, girls are more likely to work than boys are (Column 3). Furthermore, the effect is significant both statistically and economically: the coefficient indicates that the probability that a girls works is 0.36 greater than boys' probability — which in relative terms means that girls are $100 \%$ more likely to work than boys. ${ }^{11}$ This finding suggests that ignoring domestic work underestimates the degree to which girls are involved in work activities that pull them away from school-related tasks. Although our estimations don't find that girls are less likely to be enrolled in school than boys (Column 4), the fact that girls are more likely to be involved in work-related activities means that they spend less time studying and doing homework, which may not affect 
enrollment but may affect their learning outcomes (Gunnarson et al., 2004).

The fact that families assign a greater share of domestic responsibilities to girls while boys are in charge of market-oriented tasks reflects that gender roles are assigned early in life. This division of labor is likely to have an effect on women's future outcomes, like their decision to participate in the labor market, career selection or occupational choice. This finding is relevant because differences between men and women's labor market outcomes are typically associated with differences in their training, experience, age, marital status, career commitment or quality of their social networks (Contreras et al., 2007). However, our finding suggests that gender role assignments take place early in life, and that if young girls feel that they are solely or mainly responsible for domestic chores, then it is possible that in the future they stay out of the labor market or choose less demanding careers to have more time for domestic activities.

We also estimated whether the work and schooling decisions are correlated and found that the correlation coefficient $\rho$ is negative and statistically significant in all estimations, which indicates that these are not independent decisions and that there is indeed a trade-off between child work and schooling. Nevertheless, the magnitude of the coefficient indicates that the trade-

off between market oriented work and schooling $(-0.48)$ is greater than the trade off between market oriented + domestic work and schooling $(-0.38)$, which reveals that domestic tasks may be more complementary with school-related activities than pure market work.

\subsection{Other Variables}

In this section we discuss results of all other explanatory variables displayed in Table 4. We find that children who live in rural areas have a higher probability of working than urban children, which could be because agriculture has a higher demand and adaptability for children's 
labor than other activities, or to cultural differences between cities and rural areas, as was discussed above.

Although parental education significantly affects children's time allocations, the effect differs across the two definitions of work. Even small amounts of schooling of the head of the household reduce pure market work (Table 4, Column 1): children living in families where the head of the household has incomplete primary education are less likely to perform marketoriented work compared to families where the household head has no education. Meanwhile total work (market + domestic) is reduced when parents obtain relatively high levels of education (Column 3): a decrease in the likelihood that children work under the inclusive definition requires that the household head have completed secondary education or more. Thus, in order to reduce both types of child work, relatively high levels of income (proxied by education) are required, perhaps because only high-income families are able to purchase domestic services in the market and thus, their children are not required to perform household tasks. ${ }^{12}$

We also find that parental education (positively) affects the likelihood of school enrollment only if the household head has completed primary education or more. These findings suggest that thresholds exist in the effect of parental education-i.e., permanent family income levels—on children's outcomes.

Wealth has the expected effect on children's outcomes. Piped water inside the household is negatively correlated with the likelihood of working for both definitions of work, and if there is electrical power inside the household, the likelihood of school enrolment is higher.

The presence of both parents in the home, and whether the head of the household is female, does not affect children's schooling and working decisions. Other household demographics do: the presence of pre-school aged children is negatively correlated with the likelihood of schooling, but only when we estimate the model considering domestic work in the 
child labor definition. This reveals that an important task in domestic activities is taking care of young siblings, and that this task is sufficiently time-intensive that it deters children from enrolling in school. The negative effect of childcare duties is missed if the child labor definition does not consider chores as work-which highlights the relevance of considering all activities that can potentially distract children from their educational tasks.

We also find that with more school-aged siblings the probability that a child aged 7 to 14 attends school decreases, suggesting that school-aged children compete for family resources or that these resources are scarce in Bolivian households. Meanwhile, the presence of an adult family member (other than parents) aged 19 years or more is correlated with a lower probability of work if work includes domestic tasks, but the effect is not statistically significant with the pure-market work definition. This finding indicates that when additional adults are present in the household, they help take care of domestic chores and alleviate the burden that younger children would otherwise face.

\subsection{Ethnicity}

Our findings also reveal that ethnicity plays an important role in determining children's outcomes. For both definitions of work, indigenous children are more likely to work and less likely to be in school than non-indigenous children with similar individual, socio-economic and household characteristics (Table 4), although the magnitude of the effect of work depends on the definition. Indigenous children are more than 200 percent more likely to work in market activities than non-indigenous children, whereas if all activities are considered, they are 38

percent more likely to work. They are also 38 percent less likely than non-indigenous children to be enrolled in school.

To further analyze the role of ethnicity, we estimated our econometric model separately 
for non-indigenous and indigenous children, and present these results in Tables 5 and 6 , respectively. Results for explanatory variables other than those shown in our tables were similar to results for all children so for brevity of exposition, they are neither presented nor discussed. ${ }^{13}$

\section{[ INSERT TABLE 5 HERE ]}

We find that the role of gender and domestic work for non-indigenous children is similar to the average finding: girls are less likely to work than boys with a market definition, and more likely to work with the market + domestic tasks definition (Table 5, Columns 1 and 3). Although the coefficient is negative, there is no statistically significant difference between the likelihood of school enrollment among girls and boys (Columns 2 and 4).

Among indigenous children (Table 6), we find that girls are just as likely to be employed

in market work as boys are (Column 1) and that they are more likely to work than boys if domestic work is considered (Column 3). Furthermore, an alarming result is that indigenous girls are less likely to be in school than indigenous boys (Columns 2 and 4), which contrasts with results for non-indigenous girls who are just as likely to be enrolled in school as boys are. This could be due to cultural differences between indigenous and non-indigenous families, specifically, to differences in the roles that women play in more traditional societies. If the expectation that women are mainly responsible for domestic responsibilities is stronger among the indigenous, then it follows that girls begin to play this role early in life and that their school achievements are not as relevant as those of indigenous boys.

\section{[ INSERT TABLE 6 HERE ]}

Further evidence reveals that ethnicity is important: the tradeoff between market work and school is greater for indigenous $(\rho=-0.61)$ than for non-indigenous children $(\rho=-0.41){ }^{14}$ Work - in either pure market or all activities - has a greater negative impact on indigenous children's school enrollment than on the non-indigenous. This could occur because the nature of 
work that children perform is different across ethnic lines, for instance if non-indigenous children's work activities are more complementary to schooling.

These findings have an important policy message: indigenous children are more vulnerable to the potentially negative effects of work, indicated by a stronger tradeoff between the two. Furthermore, among indigenous children, girls are especially at risk since they are less likely to be enrolled in school than indigenous boys.

\section{Conclusions and final remarks}

Empirical research has revealed that working as a child results in lower earnings as an adult, which may occur because working children acquire less education or if the quality of their learning is negatively affected by work. Most studies have not measured the effect of child labor on schooling directly because they are simultaneously determined. In this study, we modeled the joint nature of these decisions and found that there is statistically significant trade-off between the work and schooling activities or children. This result reveals only part of the harmful effects of work on schooling, since our data limits the analysis to school enrollment. However, the negative effects of work go beyond enrollment, since it has also been found to affect school attainment (Psacharopoulos, 1997; Ray 2000) and the quality of children's learning (Gunnarsson et al. 2004).

The definition of child labor that most empirical studies have used considers only economic activities, ignoring the fact that children spend important amounts of time performing household chores, especially girls. We find that in Bolivia girls are twice as likely to work 20+ weekly hours than boys if the definition of work includes domestic activities. Although girls are just as likely to be enrolled in school as boys are, dedicating time to both market and domestic activities conflicts directly with after-school tasks (homework, studying, etc.) that are important 
for success in other education outcomes such as dropout or repetition rates, and cognitive learning.

Indigenous boys are less likely to enroll in school than other children, and indigenous girls are less likely than indigenous boys to be in school. Thus, indigenous children — especially indigenous girls - are at serious risk of falling behind other children in terms of their education achievements. The presence of more school-aged children in the household reduces the likelihood that a child enrolls in primary school, suggesting that family size is negatively correlated with schooling and/or that households in Bolivia have limited resources to dedicate to children's schooling.

We find important intra-household substitution of labor. First, the presence of an adult family member other than the child's parents in the household decreases the probability that a child works under the inclusive definition of work that includes domestic tasks. This reveals that adults can alleviate the burden of household chores that children face. Second, the presence of a pre-school aged sibling (aged 5 or younger) is negatively correlated with the likelihood of children's schooling when the work definition includes domestic tasks. This latter finding suggests that the availability of alternative childcare would help increase the likelihood that some children attend school. Public investments in pre-school programs would have positive effects not only on the preschoolers themselves, but also on older siblings, who would otherwise have to stay home to care for them.

The measurement of domestic activities as work reveals that girls are relatively more responsible for performing domestic work relative to boys, which will have important effects in their adult lives even if their school enrollment is not. This study finds evidence that traditional gender roles are assigned very early in life in Bolivia, augmenting the likelihood that women shy away from participating in the labor market or from seeking more demanding (better-paid) 
economic activities. Indigenous girls are in serious risk of falling behind other children in terms of their schooling outcomes, and if traditional gender roles affect future economic opportunities and outcomes, then they are especially vulnerable to living in poverty and exclusion as adults. 


\section{References}

Amin, S., Quayes S. and Rives J., 2006, "Market work and household work as deterrents to schooling in Bangladesh," World Development, Vol. 34: 1271-1286.

Basu K., Tzannatos Z., 2003. "The Global Child Labor Problem: What Do We Know and What Can We Do?", World Bank Economic Review, Vol.17, No 2.

Bhalotra S. Tzannatos Z., 2003. “Child Labor: What Have We Learnt?”, Social Protection Discussion Paper Series, No.317, World Bank.

Contreras, D., Kruger, D.I., Zapata, D. 2006. "Economic Opportunities for Indigenous People in Bolivia.” Background paper for: Economic Opportunities for Indigenous Peoples in Latin America, The World Bank.

Contreras, D., Kruger, D.I., Ochoa, M., Zapata, D. 2007. "The role of social networks in employment outcomes of Bolivian women.” Mimeo.

ECLAC (Economic Commission for the Latin American and the Caribbean), 2004. "Panorama Social de América Latina 2003”.

Edmonds, E.V. (2006) Understanding Sibling Differences in Child Labor. Journal of Population Economics, 19(4), pp.795-821.

Edmonds, E., 2007, “Child labor”, Darmouth College, IZA and NBER, mimeo.

Gunnarsson, V., Orazem P., and Sanchez M., 2004, "Child labor and school achievement in Latin America", World Bank Economic Review 20: 31-54

International Labor Organization (ILO), 1998. “Trabajo Infantil en los Países Andinos: Bolivia, Colombia, Ecuador, Perú y Venzuela", No. 75.

Kruger D., Berthelon M., "Work and schooling: the role of household activities among girls in Brazil”, mimeo, Pontifica Universidad Católica de Valparaíso. 
Levinson D., Moe K., Knaul F., 2001. "Youth Education and Work in Mexico", World Development, Vol. 29, No.1: 167-188.

Levison, D. and Moe K., 1998, "Household work as a deterrent to schooling: An analysis of adolescent girls in Peru." Journal of Developing Areas, Vol.32: 339-356.

Moehling, C., 2005 "She has suddenly become powerful: youth employment and household decision making in the early twentieth century," Journal of Economic History, Vol. 65: 414-438.

Psacharopoulos, G., 1997, “Child labour versus educational attainment: Some evidence from Latin America", Journal of Population Economics Vol. 10: 377-386.

Ray, R., 2000 "Analysis of child labour in Peru and Pakistan: A comparative study", Journal of Population Economics Vol. 13: 3-19.

Schultz, T. P. 2001, 'School Subsidies for the Poor: Evaluating the Mexican Progresa Poverty Program', Yale University, Economic Growth Center Paper No. 834.

Wahba, J., 2006, "The influence of market wages and parental history on child labour and schooling in Egypt." Journal of Population Economics, Vol.19(4), pp.823-852. 
Figure 1

Work Rates, by Gender and Age

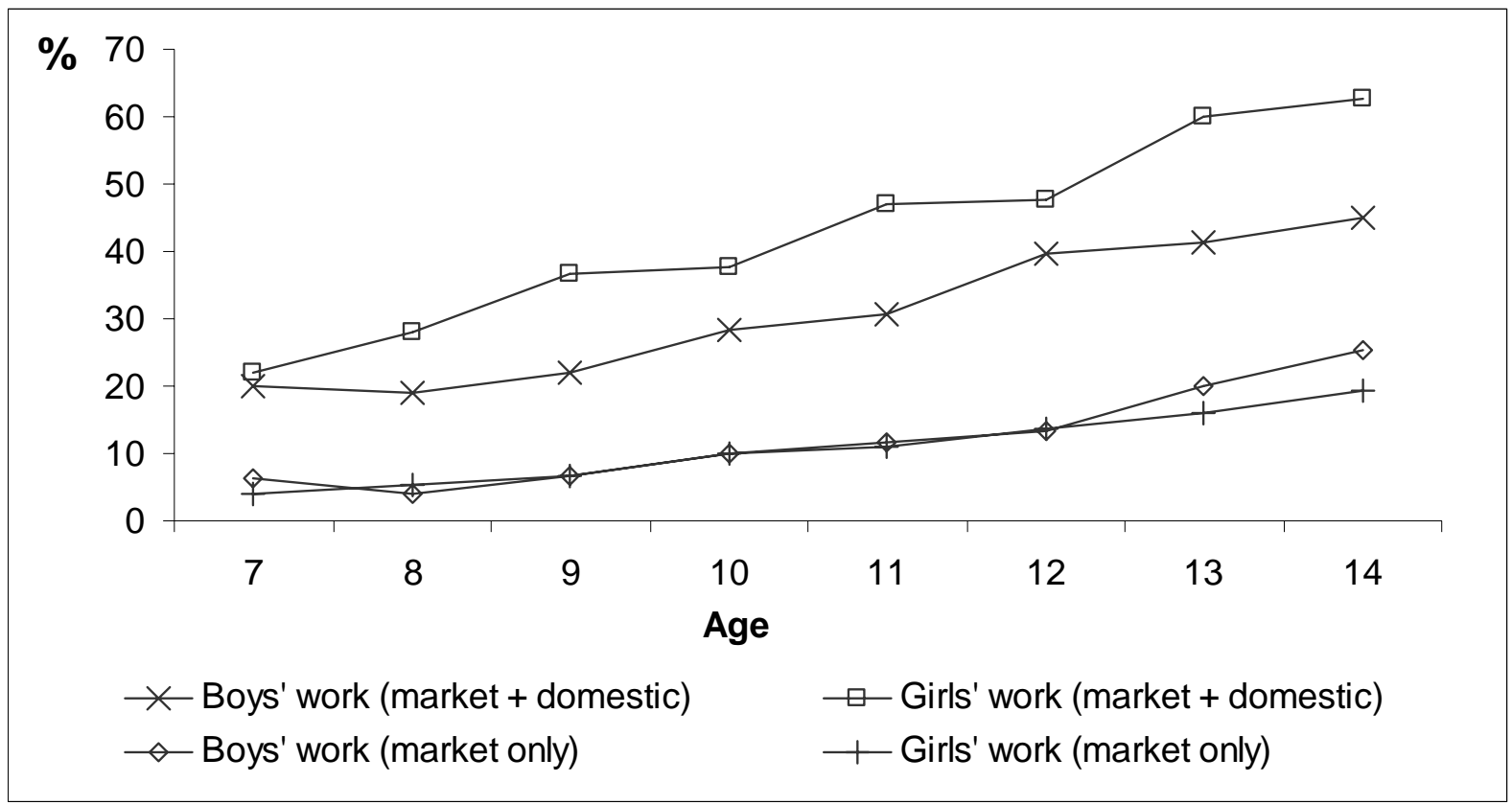

Authors' estimates based on MECOVI 2001. Includes children aged 7 to 14 years. 
Figure 2

Work Rates, by Ethnicity and Age

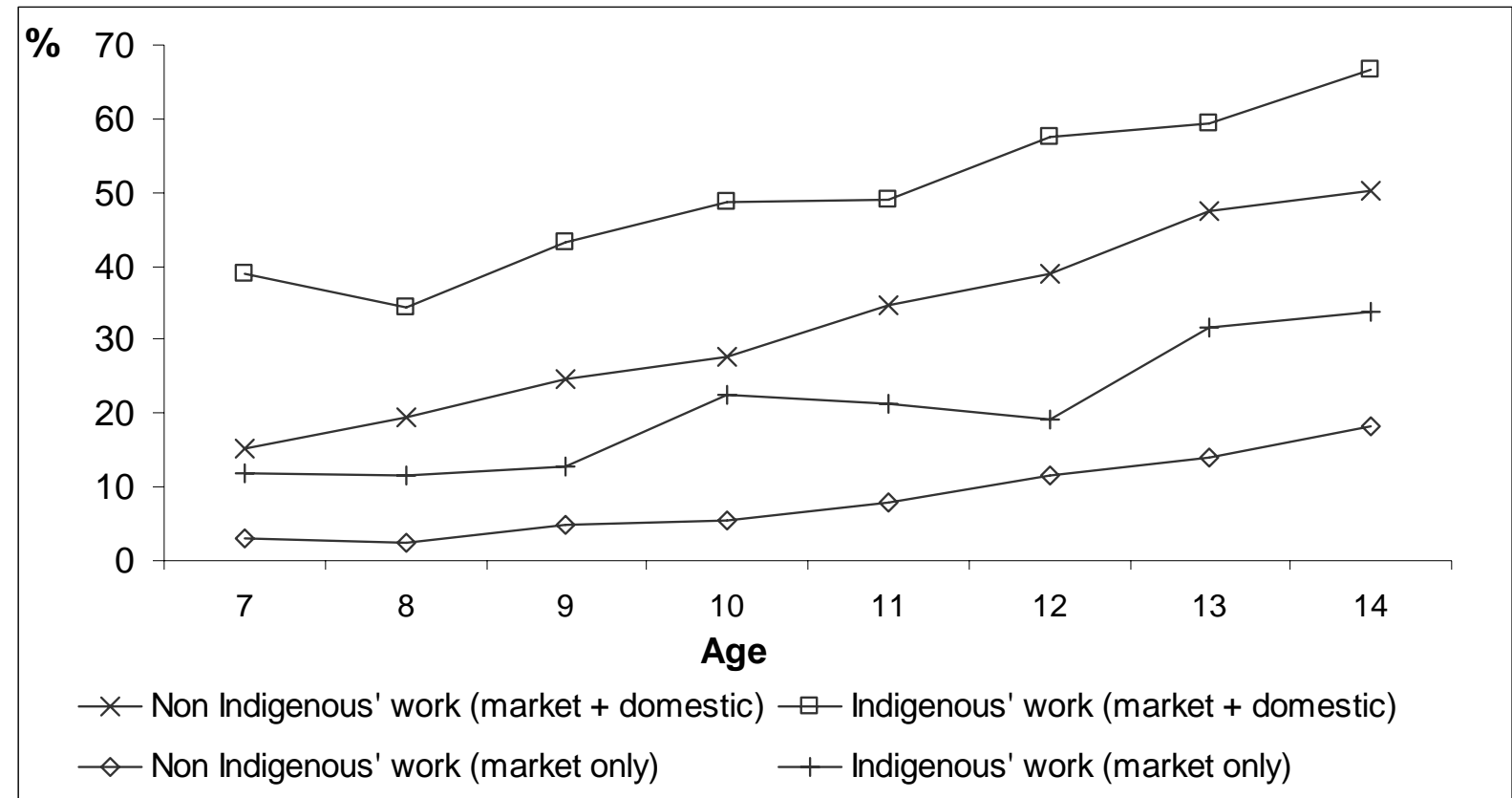

Authors' estimates based on MECOVI 2001. Includes children aged 7 to 14 years. 
Table 1: Incidence (\%) and intensity of work outcomes in Bolivia,by gender and ethnicity

\begin{tabular}{|c|c|c|c|c|c|}
\hline Outcome & Boys & Girls & $\begin{array}{c}\text { Non } \\
\text { Indigenous } \\
\end{array}$ & Indigenous & Total \\
\hline Performed at least 1 hour of domestic work? & 83.8 & 89.8 & 85.0 & 92.1 & 86.8 \\
\hline Ave. hours/week (conditional on domestic work) & 12.0 & 16.9 & 14.4 & 14.7 & 14.5 \\
\hline Worked in market activities at least 1 hour? & 32.0 & 25.4 & 18.7 & 58.8 & 28.7 \\
\hline Ave. hours/week (conditional on working) & 21.2 & 20.8 & 22.8 & 19.3 & 21.0 \\
\hline $\begin{array}{l}\text { Performed at least } 1 \text { hour of any type of work } \\
\text { (domestic or market)? }\end{array}$ & 80.1 & 86.4 & 80.3 & 92.0 & 83.2 \\
\hline Ave. hours/week (conditional on working) & 20.3 & 23.2 & 20.2 & 25.9 & 21.8 \\
\hline
\end{tabular}

Authors' estimates based on MECOVI 2001. Includes children aged 7 to 14 years. 
Table 2

Work and School Enrollment Rates, by gender and ethnicity

\begin{tabular}{|c|c|c|c|c|c|c|c|c|}
\hline & \multicolumn{4}{|c|}{ Without Domestic Work } & \multicolumn{4}{|c|}{ With Domestic Work } \\
\hline & $\begin{array}{c}\text { Only } \\
\text { Studying }\end{array}$ & $\begin{array}{c}\text { Only } \\
\text { Working }\end{array}$ & $\begin{array}{c}\text { Studying } \\
\& \\
\text { Working }\end{array}$ & None & $\begin{array}{c}\text { Only } \\
\text { Studying }\end{array}$ & $\begin{array}{c}\text { Just } \\
\text { Working }\end{array}$ & $\begin{array}{c}\text { Studying } \\
\& \\
\text { Working }\end{array}$ & None \\
\hline $\begin{array}{c}\text { All } \\
\text { Children }\end{array}$ & 85.8 & 2.1 & 9.2 & 3.0 & 62.4 & 3.7 & 32.6 & 1.4 \\
\hline Boys & 85.6 & 2.4 & 9.4 & 2.5 & 68.1 & 3.5 & 26.9 & 1.4 \\
\hline Girls & 85.9 & 1.7 & 8.9 & 3.5 & 56.5 & 3.9 & 38.3 & 1.3 \\
\hline $\begin{array}{c}\text { Non- } \\
\text { Indigeneous }\end{array}$ & 89.4 & 1.3 & 7.0 & 2.4 & 66.8 & 2.5 & 29.5 & 1.2 \\
\hline Indigeneous & 74.9 & 4.5 & 15.9 & 4.8 & 48.9 & 7.4 & 41.9 & 1.9 \\
\hline
\end{tabular}

Author's estimates based on MECOVI 2001. Includes children aged 7 to 14 years.

Working children worked at least 20 hours per week in either market or domestic activities. 


\section{Table 3}

Descriptive Statistics

\begin{tabular}{lcccc}
\hline \hline Variable & Mean & SD & Min & Max \\
\hline Work rate-Restrictive Definition & 0.11 & 0.32 & 0 & 1 \\
Work rate-Inclusive Definition & 0.36 & 0.48 & 0 & 1 \\
School Enrollment & 0.95 & 0.22 & 0 & 1 \\
Female & 0.50 & 0.50 & 0 & 1 \\
Indigenous & 0.25 & 0.43 & 0 & 1 \\
Age & 10.43 & 2.28 & 7 & 14 \\
Rural & 0.40 & 0.49 & 0 & 1 \\
Female-headed Hhold. & 0.17 & 0.37 & 0 & 1 \\
Both parents present & 0.76 & 0.43 & 0 & 1 \\
Head of HH-incomp. primary educ. & 0.52 & 0.50 & 0 & 1 \\
Head of HH-complete. primary educ. & 0.12 & 0.33 & 0 & 1 \\
Head of HH-complete. Second. ed. & 0.20 & 0.40 & 0 & 1 \\
No. family members 6 yrs. or less & 0.88 & 1.01 & 0 & 7 \\
No. family members 6 to 18 years & 1.88 & 1.33 & 0 & 9 \\
No. family members 19 years + & 0.62 & 1.01 & 0 & 8 \\
Pipped water in household & 0.64 & 0.48 & 0 & 1 \\
Electricity in household & 0.67 & 0.47 & 0 & 1 \\
\hline Number of Observations & \multicolumn{5}{c}{5,277} \\
\hline \hline Authors' estimates from MECOVI 2001. Includes children aged 7 to 14 years.
\end{tabular}


Table 4: All Children aged 7 to 14 years

Child work and school enrollment - Bivariate Probit Regressions

\begin{tabular}{|c|c|c|c|c|}
\hline \multirow[b]{2}{*}{ Explanatory variable } & \multicolumn{2}{|c|}{ Market work } & \multicolumn{2}{|c|}{ "Market + Domestic work } \\
\hline & Work & In School & Work & In School \\
\hline \multirow[t]{2}{*}{ Female } & -0.103 & -0.082 & $0.387 * * *$ & -0.073 \\
\hline & $(0.067)$ & $(0.086)$ & $(0.049)$ & $(0.085)$ \\
\hline \multirow[t]{2}{*}{ Rural } & $0.365 * * *$ & -0.074 & $0.406^{* * *}$ & -0.055 \\
\hline & $(0.110)$ & $(0.143)$ & $(0.084)$ & $(0.140)$ \\
\hline \multirow{2}{*}{ Indigenous } & $0.269 * *$ & $-0.360 * * *$ & $0.138^{*}$ & $-0.378 * * *$ \\
\hline & $(0.110)$ & $(0.134)$ & $(0.084)$ & $(0.133)$ \\
\hline \multirow[t]{2}{*}{ Age } & 0.041 & $1.123 * * *$ & $0.211 *$ & $1.126^{* * *}$ \\
\hline & $(0.161)$ & $(0.186)$ & $(0.118)$ & $(0.188)$ \\
\hline \multirow[t]{2}{*}{$\mathrm{Age}^{2}$} & 0.006 & $-0.058 * * *$ & -0.002 & $-0.058 * * *$ \\
\hline & $(0.008)$ & $(0.009)$ & $(0.006)$ & $(0.009)$ \\
\hline \multirow[t]{2}{*}{ Female-headed HHold. } & 0.015 & 0.195 & 0.106 & 0.189 \\
\hline & $(0.137)$ & $(0.187)$ & $(0.097)$ & $(0.191)$ \\
\hline \multirow[t]{2}{*}{ Both parents present } & -0.020 & 0.164 & 0.117 & 0.174 \\
\hline & $(0.116)$ & $(0.162)$ & $(0.083)$ & $(0.162)$ \\
\hline \multirow[t]{2}{*}{ Head of HH-incomp. primary ed. } & $-0.247 * * *$ & 0.097 & -0.098 & 0.093 \\
\hline & $(0.096)$ & $(0.097)$ & $(0.071)$ & $(0.099)$ \\
\hline \multirow[t]{2}{*}{ Head of HH-compl. primary ed. } & -0.196 & $0.486 * *$ & -0.066 & $0.479 * *$ \\
\hline & $(0.144)$ & $(0.226)$ & $(0.103)$ & $(0.234)$ \\
\hline \multirow[t]{2}{*}{ Head of HH-compl. secondary ed.+ } & $-0.524 * * *$ & $0.679 * * *$ & $-0.523 * * *$ & $0.639 * * *$ \\
\hline & $(0.154)$ & $(0.225)$ & $(0.095)$ & $(0.225)$ \\
\hline \multirow[t]{2}{*}{ No. family members 6 years or less } & $-0.062 *$ & -0.063 & 0.033 & $-0.073 *$ \\
\hline & $(0.037)$ & $(0.041)$ & $(0.026)$ & $(0.041)$ \\
\hline \multirow[t]{2}{*}{ No. family members 6 to 18 years } & -0.018 & $-0.074 * * *$ & -0.006 & $-0.074 * * *$ \\
\hline & $(0.027)$ & $(0.028)$ & $(0.019)$ & $(0.028)$ \\
\hline \multirow[t]{2}{*}{ No. family members 19 years +} & -0.036 & -0.047 & $-0.056^{* *}$ & -0.035 \\
\hline & $(0.038)$ & $(0.039)$ & $(0.026)$ & $(0.038)$ \\
\hline \multirow[t]{2}{*}{ Piped water in household } & $-0.195 * *$ & 0.142 & $-0.139 *$ & 0.146 \\
\hline & $(0.093)$ & $(0.100)$ & $(0.074)$ & $(0.102)$ \\
\hline \multirow[t]{2}{*}{ Electricity in household } & -0.107 & $0.621 * * *$ & -0.090 & $0.631 * * *$ \\
\hline & $(0.118)$ & $(0.125)$ & $(0.084)$ & $(0.126)$ \\
\hline \multirow[t]{2}{*}{ Constant } & $-2.360 * * *$ & $-3.505 * * *$ & $-2.647 * * *$ & $-3.477 * * *$ \\
\hline & $(0.869)$ & $(1.036)$ & $(0.631)$ & $(1.040)$ \\
\hline Average Outcome & 0.113 & 0.949 & 0.363 & 0.949 \\
\hline Observations & \multicolumn{2}{|c|}{5277} & \multicolumn{2}{|c|}{5277} \\
\hline Correlation coefficient $(\rho)$ & \multicolumn{2}{|c|}{-0.477} & \multicolumn{2}{|c|}{-0.377} \\
\hline Wald test $\mathrm{rho}=0$ chi 2 & \multicolumn{2}{|c|}{67.206} & \multicolumn{2}{|c|}{45.219} \\
\hline
\end{tabular}

Robust standard errors are reported in parentheses. Estimations include municipal fixed effects and used expansion factors. * significant at $10 \%$; ** significant at $5 \% ; * * *$ significant at $1 \%$ 
Table 5: Non-indigenous children aged 7 to 14 years

Child work and school enrollment - Bivariate Probit Regressions

\begin{tabular}{lllll}
\hline \hline \multirow{2}{*}{ Explanatory variable } & \multicolumn{2}{c}{ Market work } & \multicolumn{2}{c}{ Market \& Domestic work } \\
Work & In School & Work & In School \\
\hline \multirow{2}{*}{ Female } & $-0.174^{* *}$ & -0.051 & $0.365^{* * *}$ & -0.048 \\
& $(0.087)$ & $(0.106)$ & $(0.059)$ & $(0.106)$ \\
Rural Area & 0.053 & 0.062 & $0.230^{* *}$ & 0.080 \\
& $(0.117)$ & $(0.150)$ & $(0.093)$ & $(0.151)$ \\
Female Household Head & 0.172 & 0.170 & $0.216^{*}$ & 0.180 \\
& $(0.188)$ & $(0.243)$ & $(0.114)$ & $(0.246)$ \\
\hline Average outcome & 0.083 & 0.963 & 0.320 & 0.963 \\
\hline Observations & \multicolumn{2}{c}{3867} & \multicolumn{3}{c}{3867} \\
Correlation coefficient $(\rho)$ & \multicolumn{2}{c}{-0.405} & \multicolumn{3}{c}{-0.332} \\
Wald test rho=0 chi2 & 28.070 & \multicolumn{3}{c}{21.424} \\
\hline
\end{tabular}

Robust standard errors are reported in parentheses. Estimations used expansion factors. * significant at $10 \%$; **

significant at $5 \% ; * * *$ significant at $1 \%$. Not shown: presence of both parents, education of hh.head, family demographics, running water and electricity inside hh, and municipal fixed effects. 
Table 6: Indigenous children aged 7 to 14 years

Child work and school enrollment, Bivariate Probit Regressions

\begin{tabular}{|c|c|c|c|c|}
\hline \multirow[b]{2}{*}{ Explanatory variable } & \multicolumn{2}{|c|}{ Market work } & \multicolumn{2}{|c|}{ Market \& Domestic work } \\
\hline & Work & In School & Work & In School \\
\hline \multirow[t]{2}{*}{ Female } & 0.045 & $-0.304 * *$ & $0.453 * * *$ & $-0.284 *$ \\
\hline & $(0.116)$ & $(0.140)$ & $(0.096)$ & $(0.146)$ \\
\hline \multirow[t]{2}{*}{ Rural Area } & $1.163 * * *$ & -0.398 & $0.463 * *$ & -0.146 \\
\hline & $(0.289)$ & $(0.375)$ & $(0.205)$ & $(0.371)$ \\
\hline \multirow[t]{2}{*}{ Female Head HH } & -0.391 & 0.468 & -0.336 & 0.362 \\
\hline & $(0.256)$ & $(0.359)$ & $(0.222)$ & $(0.360)$ \\
\hline Average Outcome & 0.203 & 0.908 & 0.493 & 0.908 \\
\hline Observations & \multicolumn{2}{|c|}{1410} & \multicolumn{2}{|c|}{1410} \\
\hline $\begin{array}{l}\text { Correlation coefficient } \\
\text { ( } \rho)\end{array}$ & \multicolumn{2}{|c|}{-0.611} & \multicolumn{2}{|c|}{-0.479} \\
\hline Wald test rho $=0$ chi 2 & \multicolumn{2}{|c|}{41.887} & \multicolumn{2}{|c|}{28.977} \\
\hline
\end{tabular}

Robust standard errors are reported in parentheses. Estimations used expansion factors. * significant at $10 \%$; ** significant at 5\%; *** significant at $1 \%$. Not shown: presence of both parents, education of hh.head, family demographics, running water and electricity inside hh, and municipal fixed effects. 


\section{NOTES}

${ }^{1}$ For recent surveys, see Edmonds (2007), Bazu and Tzannatos (2003), and Bhalotra and Tzannatos (2003).

${ }^{2}$ Depending its definition, between 30 to 40 percent of Bolivia's population is indigenous. In this paper, we define a child as indigenous based on his or her mother tongue.

${ }^{3}$ World Bank, World Development Indicators Database.

${ }^{4}$ Authors estimates from MECOVI 2001.

${ }^{5}$ The cut-off point of 20 hours is widely used in the child labor literature, since it is equivalent to 50 percent of an adult full-time work week. This criterion implicitly assumes that work activities that are less time-intensive do not conflict with educational goals.

${ }^{6}$ The precise question of the MECOVI survey asks "did you enroll in a primary or secondary grade or collage during this year?"

${ }^{7}$ The MECOVI questions to define market work were "did you work last week?" and "if not, were you absent due to sickness, vacation, labor strike, adverse weather, etc.?" To define domestic work, the question was: "During the previous week, did you carry out any of the following activities within your household? Take care of children and/or elderly family members; cook and clean the household; wash and/or iron clothes; perform minor household repairs; shop for food; chop and carry firewood; carry water from external water source; organize and maintain neatness.

${ }^{8}$ As in Levinson and Moe (1998) we assume that the household composition is exogenously determined in the short run.

${ }^{9}$ Nearly $90 \%$ of the children in our sample are daughters or sons of the household head so that this variable is a proxy for parental education. We explored if not being a son/daughter of the household head had an impact on children's outcomes and found that it does not. 
${ }^{10}$ See Wahba (2006). Informality rates are high in Bolivia: almost 50 and 90 percent in urban and rural areas, repectively (Contreras et al., 2006).

${ }^{11}$ All marginal effects discussed are estimated by dividing the coefficient by the average of the dependent variable, in this case, the child work rate of 0.36 (Table 2).

${ }^{12}$ Indeed we find that in Bolivia, 80 percent of households that report hiring one or more maids have heads of households that completed a high-school degree or more.

${ }^{13}$ Results available from the authors upon request.

14 The same is true for the tradeoff between total work and school for indigenous $(\rho=-0.48)$ vs. non-indigenous children $(\rho=-0.33)$. 